\title{
Atrial Pacing to Estimate Total Sinoatrial Conduction Time in Children
}

\author{
Robert M. Campbell, Macdonald Dick II, Dennis C. Crowley, Albert P. Rocchini, \\ A. Rebecca Snider, and Amnon Rosenthal \\ Division of Pediatric Cardiology, C.S. Mott Children's Hospital, Department of Pediatrics, \\ University of Michigan, Ann Arbor, Michigan, USA
}

\begin{abstract}
SUMMARY. No data exist concerning the total sinoatrial conduction time (TSACT) in children that compare values determined by the atrial extrastimulation technique (TSACT, s $_{\mathbf{s}}$ with those generated by the atrial pacing method (TSACT $\mathrm{N}_{\mathrm{N}}$. In this study, TSACT in 55 patients, age 0.2-18.5, was measured using both techniques. TSACT $\mathrm{N}_{\mathrm{N}}$ was performed at a mean $90 \%$ (TSACT $\left._{\mathrm{N}-90}\right)(n=32)$ or a mean $95 \%$ (TSACT $_{\mathrm{N}-95}$ and $(n=38)$ of sinus cycle length (SCL). When data generated during determination of TSACT $_{\mathbf{N}-90}$ and TSACT $_{\mathbf{S}}$ were compared, $S C L$ and recovery cycle length (REC) were similar for both techniques. Likewise, TSACT $_{S}(128 \pm$ $40 \mathrm{~ms})$ and $\mathrm{TSACT}_{\mathrm{N}-90}(126 \pm 74 \mathrm{~ms})$ were not significantly different. Coefficient of correlation was $r=0.82, p<0.001$. Chi-square analysis demonstrated a strong association of normal and abnormal values between TSACT $_{S}$ and TSACT $_{\mathbf{N - 9 0}}$. In contrast, when values generated during

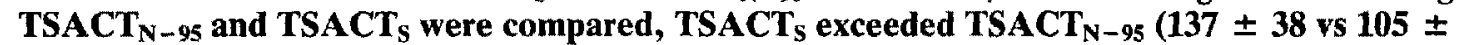
$58 \mathrm{~ms} ; p<0.001)$. Values for SCL and REC were similar while correlation between TSACT determined by the two techniques remained strong $(r=0.82, p<0.001)$. Despite a good

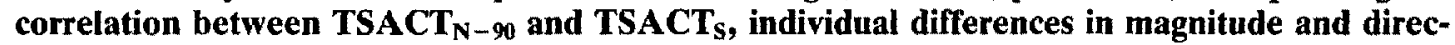
tion were noted between the two techniques.

In summary, TSACT $_{\mathbf{N}-90}$ approximates TSACT $_{S}$ in children. TSACT $_{\mathbf{N}-90}$ is preferable to TSACT $_{\mathrm{N}-95}$, probably due to more complete sinus node capture during atrial pacing. However, the behavior of the sinus node in response to extrastimuli (single or train) precludes favoring one technique over the other. More precise evaluation of sinoatrial conduction will require direct recording of sinus node activity.
\end{abstract}

KEY WORDS: Sinoatrial conduction - Atrial pacing

In 1973, Strauss et al, introduced a programmed atrial extrastimulus technique to measure indirectly total sinoatrial conduction time (TSACT) during electrophysiologic study in man [14]. In 1978, Narula et al. proposed a constant high right atrial pacing technique for indirect TSACT measurements [11]. Alleged advantages of the pacing method include: shorter time for analysis of data, elimination of indeterminant reset-zone responses occasionally encountered when defining the TSACT using the extrastimulation method, and less complexity of the stimulator. Although values between the two methods may vary in both direction

Address reprint requests to: Dr. Macdonald Dick II, Section of Pediatric Cardiology, Room F1126, Box 0204, University of Michigan Medical Center, 1500 East Medical Center Drive, Ann Arbor, MI 48109-0204, USA. and magnitude within individual human subjects and experimental animals (rabbits), studies in adults have found a good correlation between the values generated by the two techniques $[6,11]$. However, no data comparing the Narula method $\left(\mathrm{TSACT}_{\mathrm{N}}\right)$ with the Strauss method (TSACT ${ }_{S}$ ) exist in children. Our interest in the comparative techniques is further heightened by the incidence of sinus node abnormalities that frequently follow surgical repair of congenital heart defects, the abrupt shifts in sinus cycle length in children rendering the extrastimulation technique difficult, and the less complex pacing approach. The purpose of this study, therefore, was to evaluate the pacing method for measuring total sinoatrial conduction time in children as well as to compare the atrial pacing method with the atrial extrastimulus method. 


\section{Materials and Methods}

The TSACT was measured using both the extrastimulus technique of extrastimulation and the constant atrial pacing technique of Narula et al. during diagnostic cardiac catheterization in 55 patients. Median age was 2.08 years; $25 \%$ of the patients were between 5.5 and 19.75 years. There were 25 female and 30 male patients. The subjects represented 55 consecutive patients studied during a one-year period at our institution exclusive of those patients who either were clinically unstable or were receiving interventional therapeutic catheterization (balloon dilatation). Sixteen of the patients were taking digoxin. Thirteen patients had undergone open-heart surgery for repair of congenital heart defects (4, ventricular septal defect; 3 , tetralogy of Fallot; 3, aortic valvulotomy; 1 , total anomalous venous return; 1 , transposition; 1, endocardial cushion defect). Among the 42 remaining patients, 15 had a ventricular septal defect, 4, an endocardial cushion defect; 4, pulmonary stenosis; 4 , patent ductus arteriosus (1 ligated); 3 , supraventricular tachycardia: 2, transposition; 2, coarctation of the aorta (both repaired); 2, tetralogy of Fallot; 2, aortic stenosis; and 1 patient each with either atrial septal defect, corrected transposition, cardiomyopathy, or tricuspid atresia. All 55 patients were free of clinical and electrocardiographic evidence suggestive of abnormal sinus node function. Informed consent was obtained for both electrophysiologic studies. The patients were sedated with diphenhydramamine (I $\mathrm{mg} / \mathrm{kg}$ up to $50 \mathrm{mg} \mathrm{p.o.)} \mathrm{and} \mathrm{morphine} \mathrm{sulfate}(0.1 \mathrm{mg} / \mathrm{kg}$ up to 10 mg i.m.). A single no. 5 French quadripolar electrode catheter was introduced into the right femoral vein and positioned in the high right atrium near the area of the sinus node. Using either a Bloom programmable stimulator or Medtronic 5325 stimulator, atrial stimulation of 2-ms pulse duration at twice diastolic threshold was delivered through the distal pair of electrodes. The high right atrial electrogram (recorded through the proximal electrode pair) and three surface electrocardiographic leads were recorded on photographic paper moving at $100 \mathrm{~mm} / \mathrm{s}$.

\section{Strauss Extrastimulation Atrial Extrastimulus Technique}

The extrastimulation atrial extrastimulus technique was performed using the Strauss technique. The mean cycle length (SCLs) was calculated by averaging ten sinus cycle lengths prior to beginning the extrastimulus scan. The following intervals were measured from the earliest onset of the atrial activation recorded from either the $P$ waves among the three simultaneous electrocardiograms or the atrial electrogram:

$$
\begin{aligned}
& A_{1} A_{1}= \text { sinus cycle length to the introduction of the premature } \\
& \text { beat } \\
& A_{1} A_{2}= \text { interval between the last spontaneous sinus beat }\left(A_{1}\right) \\
& \text { and the stimulated atrial beat }\left(A_{2}\right) \\
& A_{2} A_{3}= \text { return cycle length } \\
& A_{3} A_{4}=\text { postreturn cycle length }
\end{aligned}
$$

The data were normalized to $A_{1} A_{1}$ and were then plotted with the relative prematurity of the stimulated atrial beat $A_{1} A_{2} / A_{1} A_{1}$ on the abscissa and the relative length of both the return cycle $A_{2} A_{3}$ / $A_{1} A_{1}$ and the postreturn cycle $A_{3} A_{4} / A_{1} A_{1}$ on the ordinate. Using this graph, two types of responses or zones were noted: (a) The zone of nonreset encompasses that period of the cardiac circle in which the premature atrial beat generated from extrastimulation collides with the exiting sinus node impulse and does not reset sinus node automaticity (the sum of the $A_{1} A_{2}$ and $A_{2} A_{3}$ intervals equals two times $A_{1} A_{1}$ ). (b) The zone of reset is where the single premature atrial stimulus is assumed to have entered the sinus node prior to its regularly scheduled discharge; the sinus node is then reset, but without affecting intrinsic sinus node automaticity ( $A_{1} A_{2}$ plus $A_{2} A_{3}$ is less than two times $A_{1} A_{1}$, and $A_{2} A_{3}$ is greater than the basic sinus cycle length $\left.\left[A_{1} A_{1}\right]\right)$. TSACT $T_{S}$ is calculated by averaging the first three well-defined reset responses for each patient using the formula TSACT $=A_{2} A_{3}-A_{1} A_{1}$, and represents the time taken by the premature atrial stimulus $\left(A_{2}\right)$ to enter the sinoatrial node (atriosinus conduction time) plus the conduction time from the next spontaneous sinoatrial node impulse to the high right atrium (sinoatrial conduction time). Lack of a welldefined reset zone is present when all $\mathrm{A}_{2} \mathrm{~A}_{3}$ responses are fully compensatory and represents sinoatrial node entrance block; this is presumably related to prolonged perinodal conduction and/or prolonged refractory period of the perinodal tissues. Thus TSACT $_{\mathrm{S}}$ in this instance cannot be determined. An estimate of sinus node overdrive suppression was made for each patient in whom a TSACT could be calculated by averaging the $A_{3} A_{4} / A_{1} A_{1}$ $\times 100(\%)$ values for each of the three reset responses. Minimal or no suppression is present when $A_{3} A_{4} / A_{1} A_{1} \times 100(\%)$ is $100 \pm$ $10 \%$; this calculated value represents recovery $\left(R E C_{S}\right)$ of the sinus impulse; if the $\mathrm{REC}_{S}$ exceeded $110 \%$, the subject's data (both TSACT $T_{S}$ and TSACT TS $_{\mathrm{N}}$ were not included in the analysis. None of the study patient' $\mathrm{REC}_{S}$ exceeded $110 \%$.

\section{Narula Constant Atrial Pacing Technique}

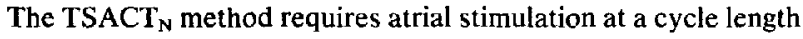
short enough to ensure atrial and sinus node capture, but long enough to prevent significant sinus node suppression. Because children exhibit a wide range of sinus cycle lengths and often sinus arrhythmia, we initially performed $\mathrm{TSACT}_{\mathrm{N}}$ at $85 \%, 90 \%$, or $95 \%$ of the patient's mean sinus cycle length obtained from the ten sinus beats prior to pacing $\left(\mathrm{SCL}_{N}\right)$. Preliminary studies in our laboratory revealed that the TSACT $T_{N}$ was best performed at either a mean cycle length equal to $90 \%$ or $95 \%$ of the resting sinus cycle length (TSACT $\mathrm{T}_{-90}$ and $\mathrm{TSACT}_{N-95}$, respectively). This preliminary analysis with a small number of subjects demonstrated a good $(r>0.8, p<0.001)$ coefficient of correlation between TSACT $T_{S}$ and TSACT $_{N}$ (using these two pacing cycle lengths), whereas pacing at $85 \%$ mean sinus cycle length yielded a weak correlation ( $r=0.66, p=0.04$ ) between the Narula and extrastimulation methods. Therefore, for this study, TSACT was performed using a train of nine (one beat was added in comparison to Narula because of stimulator design) paced high right atrial beats normalized to either $88 \%-92 \%$, mean $90 \%(n=$ $32)$, or $93 \%-97 \%$, mean $95 \%(n=38)$ of the $S C L_{N} ; 15$ patients had TSACT $\mathrm{N}$ performed at both pacing cycle lengths. Following these nine placed atrial beats, the return and postreturn cycles were recorded. At least ten beats were observed before initiating the next pacing cycle. The total sinoatrial conduction time was calculated by subtracting the $S C L_{N}$ from the return cycle length; this interval represented the sum of the conduction time into and out of the sinus node, assuming no change in sinus node automaticity. TSACT $T_{N}$ was obtained by averaging 3-10 separate measurements in each patient. The postreturn cycle length is analogous to the extrastimulation $\mathrm{A}_{3} \mathrm{~A}_{4}$ interval; overdrive suppression of the sinus node $\left(\mathrm{REC}_{\mathrm{N}}\right)$ could then be assessed using the formula (postreturn cycle length $/ \mathrm{SCL}$ ) $\times 100(\%)$; if the $\mathrm{REC}_{\mathrm{N}}$ exceeded $110 \%$, the subject's data (both $\mathrm{TSACT}_{\mathrm{S}}$ and TSACT $_{\mathrm{N}}$ ) were not included in the analysis. None of the study patients' REC $_{\mathrm{N}}$ exceeded $110 \%$. 


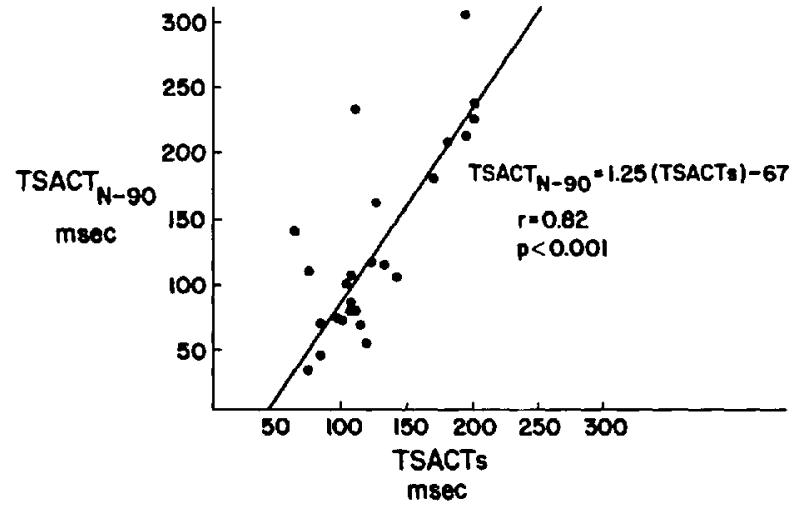

Fig. 1. Total sinoatrial conduction time estimated by the atrial extrastimulation method (TSACT S $_{\mathrm{S}}$ plotted against the atrial pacing method performed at $90 \%$ mean sinus cycle length TSACT $_{\mathrm{N}-90}$. The coefficient of correlation is $r=0.82, p<0.001$.

\section{Analysis of Data}

Sinus cycle length ( $\mathrm{SCL}$ ), total sinoatrial conduction time, and estimate of sinus node overdrive suppression (REC) for the two methods were compared using Student's $t$-test for paired data. Intrapatient variability - among the three reset responses used to calculate TSACT , and the separate measurements of postreturn $\mathrm{CL}_{-S_{\mathrm{N}}}$ used to calculate $\mathrm{TSACT}_{\mathrm{N}}$ - was assessed in each patient using the coefficient of variability. Correlation between TSACT $_{S}$ and TSACT $_{N}$ at each mean placed cycle length was determined using least-square regression analysis. All data were expressed as the mean and 1 standard deviation.

\section{Results}

\section{$T S A C T_{S}$ us $T S A C T_{N-90}$}

When data generated by the pacing technique performed at a mean of $90 \%$ of the sinus cycle length was compared with data generated by the extrastimulation technique, resting SCL $(576 \pm 152 \mathrm{~ms}$ [extrastimulation] vs $574 \pm 149 \mathrm{msec}$ [pacing]) and REC (101.9 $\pm 1.7 \%$ [extrastimulation] vs $104.4 \pm$ $6.1 \%$ [pacing]) were similar. Likewise, $\mathrm{TSACT}_{\mathrm{S}}$ $(128 \pm 40 \mathrm{~ms})$ and $\mathrm{TSACT}_{\mathrm{N}-90}(126 \pm 74 \mathrm{~ms})$ were not significantly different and demonstrated a strong correlation ( $r=0.82, p<0.001$; Fig. 1). Sinoatrial node entrance block was present in six of 32 patients using the extrastimulation method (Table 1); $\mathrm{TSACT}_{\mathrm{N}-90}$ for these patients averaged 188 ms (range 97-276 ms). In the remaining 26 patients, TSACT $_{S}$ exceeded TSACT $T_{N}$ in 16 patients, whereas TSACT $_{N}$ exceeded TSACT $T_{S}$ in ten. These differences were $\leq 30 \mathrm{~ms}$ in 14 subjects, $31-45 \mathrm{~ms}$ in eight subjects, and $>45 \mathrm{~ms}$ four subjects (Table 1 ). For patients with age-related normal TSACT $_{S}$ values $(120 \pm 20 \mathrm{~ms})$ [5], TSACT $_{\mathrm{N}-90}$ tended to underesti-
Table 1. Comparison of TSACT $T_{S}$ to TSACT $_{\mathrm{N}-90}$

\begin{tabular}{|c|c|c|}
\hline $\begin{array}{l}\text { Patient } \\
\text { no. }\end{array}$ & $\begin{array}{l}\text { TSACT }_{\mathrm{S}} \\
\text { (ms) }\end{array}$ & $\begin{array}{l}\text { TSACT }_{N-93} \\
\text { (ms) }\end{array}$ \\
\hline 1 & 74 & 32 \\
\hline 2 & 75 & 108 \\
\hline 3 & 84 & 68 \\
\hline 4 & 86 & 44 \\
\hline 5 & 97 & 74 \\
\hline 6 & 100 & 72 \\
\hline 7 & 104 & 100 \\
\hline 8 & 106 & 78 \\
\hline 9 & 107 & 86 \\
\hline 10 & 107 & 106 \\
\hline 11 & 109 & 79 \\
\hline 12 & 112 & 234 \\
\hline 13 & 113 & 68 \\
\hline 14 & 119 & 53 \\
\hline 15 & 120 & 122 \\
\hline 16 & 124 & 117 \\
\hline 17 & 127 & 163 \\
\hline 18 & 133 & 114 \\
\hline 19 & 139 & 68 \\
\hline 20 & 143 & 105 \\
\hline 21 & 171 & 181 \\
\hline 22 & 183 & 211 \\
\hline 23 & 196 & 214 \\
\hline 24 & 196 & 310 \\
\hline 25 & 203 & 227 \\
\hline 26 & 203 & 239 \\
\hline 27 & SANEB & 97 \\
\hline 28 & SANEB & 100 \\
\hline 29 & SANEB & 171 \\
\hline 30 & SANEB & 227 \\
\hline 31 & SANEB & 255 \\
\hline 32 & SANEB & 276 \\
\hline
\end{tabular}

SANEB, sinoatrial node entrance block; $\mathrm{TSACT}_{\mathrm{N}-\infty}$ total sinoatrial conduction time, determined by the Narula atrial pacing method at $90 \%$ sinus cycle length; and $\mathrm{TSACT}_{5}$, total sinoatrial conduction time, determined by the Strauss method.

mate $\mathrm{TSACT}_{\mathrm{S}}$. Although differences in direction and magnitude were observed between values obtained by the two techniques, when the subjects were stratified into normal (TSACT $<160 \mathrm{~ms}^{4}$ ) or abnormal ( $>160 \mathrm{~ms}$ [5]) groups, there was strong association $\left(\chi^{2}=17.2, p<0.001\right)$ between TSACT, and TSACT $_{\mathrm{N}-40}$. Specifically only two patients (nos. 12 and 17 ) of the 20 who had age-related normal TSACT $_{S}$ had a TSACT $_{\mathrm{N}-90}$ value $>160 \mathrm{~ms}$; similarly, only two of 12 patients (nos. 27 and 28) who had abnormal TSACT (i.e., prolonged [ $>160$ $\mathrm{ms}$ ] or sinoatrial node entrance block) exhibited normal TSACT $T_{N}$. Coefficient of variability for the pacing method was $33 \%$; for the extrastimulation technique, $7 \%$. Digoxin tended to be associated with shorter cycle lengths as well as shorter TSACT determined by both techniques, but only $(p \leq 0.05)$ among patients $<5$ years of age. In addition, a 
shorter TSACT $T_{N}$ when compared with $\mathrm{TSACT}_{\mathrm{S}}$ was noted among patients taking digitalis, but only ( $p \leq$ 0.05 ) in the children $\leq 1$ year of age. In contrast, the history of operation tended to be associated with longer sinus cycle lengths and longer TSACT by both methods, but again only ( $p \leq 0.05$ ) in the children $\leq 1$ year of age.

\section{$T S A C T_{S}$ us $T S A C T_{N-95}$}

When data generated by the pacing technique performed at a mean of $95 \%$ of the resting sinus cycle length were compared with those generated by the extrastimulation technique, no significant differences were found between SCL $(572 \pm 129$ ms [extrastimulation] vs $576 \pm 125 \mathrm{~ms}$ [pacing]) or REC (101.3 $\pm 1.9 \%$ [extrastimulation] vs $102.9 \pm 5.7 \%$ [pacing]). However, TSACT $_{S}$ was significantly greater than $\mathrm{TSACT}_{\mathrm{N}-95}(137 \pm 38 \mathrm{~ms}$ vs $105 \pm 58$ $\mathrm{ms} ; p<0.001)$. The coefficient of correlation between the two techniques was $0.82 ;(p<0.001)$. For the nine of 38 patients with sinoatrial node entrance block, TSACT $_{\mathrm{N}-95}$ averaged $216 \mathrm{~ms}$ (range $109-390 \mathrm{~ms}$ ). In 24 of the remaining 29 patients without sinoatrial node entrance block, $\mathrm{TSACT}_{\mathrm{S}}$ exceeded TSACT $\mathrm{T}_{\mathrm{N}-95}$. Coefficient of variability for the pacing technique was $42 \%$ and, for the extrastimulation technique, $6 \%$.

\section{Discussion}

Our study in children comparing the extrastimulus and atrial pacing methods designed to estimate sinoatrial conduction time yields results similar to those studies in adults $[3,6,8,11]$. Despite the demonstration of a good correlation between the TSACT produced by the atrial extrastimulation method and that produced by the atrial pacing method performed at $90 \%$ SCL, marked and unpredictable differences between the two techniques within and between individuals were observed. On the other hand, our study demonstrated, by chisquare analysis, a strong association of normal and abnormal ( $>2$ standard deviations beyond the mean of age-related normal [5]) values between TSACT $_{S}$ and $\operatorname{TSACT}_{\mathrm{N}-90}$. The study further demonstrated that pacing at $95 \%$ SCL resulted in significantly different mean values for $\mathrm{TSACT}_{\mathrm{N}}$ and $\mathrm{TSACT}_{\mathrm{S}}$, while pacing at $85 \%$ mean sinus cycle length produced a poor correlation between TSACT values generated by the two different methods.

The probable reasons for the discrepancy between the two methods are several. Critical to the success of the pacing technique is the stimulation rate. In their original study in adult patients, Narula et al. reported prolongation of TSACT associated with an increase in the atrial pacing rate [11]. This prolongation was attributed to either a rate-related delay in conduction into the sinus node (analogous to the atrioventricular node) and/or depression of sinus node automaticity. Intracellular and extracellular studies in isolated rabbit right atrial preparations [8] as well as studies in man using direct recording of sinus node electrograms $[6,7]$ have supported the concept of rate-related sinoatrial conduction delay. Another factor that can delay TSACT is pacing-induced and rate-related (both extrastimulation and train) pacemaker depression [2, $8,15]$ and perhaps shift to sites of lesser intrinsic heart rates [1]; this subtle, mild degree of sinus node depression or shift may be overlooked by our clinical estimation (REC). At the same time, incomplete sinus node capture may occur at slower pacing rates (e.g., TSACT $_{\mathrm{N}-95}$, in our own subjects); atrial capture without sinus capture or even sinus node acceleration can occur at slower pacing rates and yield a shorter $\operatorname{TSACT}_{N}[7,8,10]$. Because young patients may exhibit a wide range of heart rates as well as a rapid acceleration in rate, it may be difficult to maintain atrial capture at a rate close to the sinus rate $(95 \% \mathrm{SCL})$. However, at faster pacing rates ( $85 \%$ SCL), an increase in the total sinoatrial conduction time may be induced due to an increase in the atriosinus conduction time. In short, $90 \%$ of the sinus cycle length appears to be the optimal cycle length that establishes reliable atrial capture and, at the same time, minimizes sinus node depression or shift. Nonetheless, rate-related (by extrastimuli) prolongation of sinoatrial conduction as well as pacing-induced pacemaker shifts and sinus node depression or even acceleration can be evoked by both the extrastimulus and pacing techniques and confound the indirect determination of conduction across the sinoatrial junction.

Although significant intrapatient variability ( $\leq 10 \%$, using the coefficient of variability) among values averaged to calculate mean $\mathrm{TSACT}_{\mathrm{N}}$ may seem to reduce the use of this technique, the mean TSACT $_{\mathrm{N}-90}$ closely approximated mean TSACT $_{S}$. Wide variations in intrasubject $\mathrm{TSACT}_{\mathrm{N}}$ values have been previously reported [8]; for reasons discussed above, variability may be secondary to incomplete sinus node capture, especially at lower pacing rates. Sinus arrhythmia and/or sinus node overdrive excitation [10] may contribute to incomplete sinus node capture in some instances. Because of this intrapatient variability, at least 3-5 separate measures of total sinoatrial conduction in each subject should be averaged to obtain mean $\mathrm{TSACT}_{\mathrm{N}}$. 
This study brings to the surface the problems inherent in the indirect evaluation of sinoatrial conduction in children. Although this study demonstrates that the pacing technique is applicable in children, requires a simpler stimulator, is best performed at a pacing cycle length of $90 \%$ of the sinus cycle length, and appears to be less labor and time intensive, the physiologic behavior of the sinus node both at baseline and in response to extrastimuli (single and train) warrants cautious interpretation of the values generated by these two techniques. Perhaps the most useful aspect of these techniques in children is for the serial evaluation of sinoatrial conduction following cardiac operations $[4,13,16,17]$. Precise determination of sinoatrial conduction will depend upon application of direct recording of sinus node activity $[7,9,12]$.

Acknowledgment. We are grateful for the expert secretarial assistance of Ms. Colleen Rauch and Ms. Sharon Badish.

\section{References}

1. Bonke FIM, Bouman LN, Van Rijn, HE (1969) Changes of cardiac rhythm in rabbit after an atrial premature beat. Circ Res 24:533-544

2. Breithardt G, Seipel L (1976) The effect of premature atrial depolarization on sinus node automaticity in man. Circulation 53:920-925

3. Breithardt G, Seipel L (1978) Comparative study of two methods of estimating sinoatrial conduction time in man. Am $J$ Cardiol 42:965-971

4. Campbell RM, Dick M, Byrum C, Behrendt DM (1984) Serial electrophysiologic observations after Mustard operation. Circulation 6:II-316A

5. Campbell RM, Dick M, Rosenthal A (1984) Cardiac arrhythmias in children. Ann Rev Med 35:397-410
6. Gomes JAC, Kang PS, El-Sherif N (1982) The sinus node electrogram in patients with and without sick sinus syndrome: techniques and correlation between directly measured and indirectly estimated sinoatrial conduction time. Circulation 66:864-873

7. Gomes JAC, Hariman RI, Chowdry IA (1984) New application of direct sinus node recordings in man: assessment of sinus node recovery time. Circulation 70:663-671

8. Grant AO, Kirkorian G, Benditt DG, Strauss HC (1979) The estimation of sinoatrial conduction time in rabbit heart by the constant atrial pacing technique. Circulation 60:597-604

9. Hariman RT, Krongrad E, Boxer RA, Weiss HB, Steeg CN, Hoffman BF (1980) Method for recording electrical activity of the sino-atrial node and automatic atrial foci during cardiac catheterization in human subjects. Am $J$ Cardiol 45:775-781

10. Lange $G$ (1965) Action of driving stimuli from intrinsic and extrinsic sources of in situ cardiac pacemaker tissues. Circ Res 17:449-459

11. Narula OS, Shantha N, Vasques M, Towne WD, Linhart JW (1978) A new method for measurement of sinoatrial conduction time. Circulation 58:706-714

12. Reiffel JA, Gang E, Gliklich J, Weiss MB, David JC, Patton NJ, Bigger JT (1980) The human sinus node electrogram: a transvenous catheter technique and a comparison of directly measured and indirectly estimated sino-atrial conduction time in adults. Circulation 62:1324-1334

13. Scott WA, Dick M, Bove EL, Behrendt DM (1986) Decreased incidence of early sinus node dysfunction following arterial switch operation. Circulation 74:11-178A

14. Strauss HC, Alan CM, Saroff AL, Bigger JT, Giardina EGV (1973) Premature atrial stimulation as a key to the understanding of sinoatrial conduction in man. Circulation 47:8693

15. Strauss HC, Bigger JT Jr, Saroff AL, Giardina EGV (1976) Electrophysiologic evaluation of sinus node function in patients with sinus node dysfunction. Circulation 53:920-925

16. Vetter VL, Horowitz LN (1982) Electrophysiologic residua and sequelae of surgery for congenital heart defects. $A m ~ J$ Cardiol 50:588-604

17. Vetter VL, Tanner C, Hardy (1987) Electrophysiologic studies after arterial switch repair of D-transposition of the great arteries. J Am Coll Cardiol 9:165A 